\title{
BAHAN AJAR KAJIAN PUISI BERBASIS KEARIFAN LOKAL (PIIL PESENGGIRI) DENGAN DUKUNGAN MEDIA INTERAKTIF PREZI PRESENTATION
}

\author{
Dewi Ratnaningsih *) \\ ratnadewydj@gmail.com \\ Pendidikan Bahasa Dan Sastra Indonesia \\ Universitas Muhammadiyah Kotabumi
}

\begin{abstract}
Abstrak
The legal basis for the application of learning based on local wisdom in higher education in Indonesia is contained in Permenristekdikti Number 44 of 2015 concerning the National Standards of Higher Education (SNPT). This is the basis of this research article. This study is entitled "Teaching Material Based on Local Wisdom (Piil Pesenggiri) with the Support of Interactive Learning Media Based on Prezi Presentation". The research objective is to design teaching materials based on local wisdom (Piil Pesenggiri) with the support of interactive learning media based on Prezi Presentation. Based on the results of the study it can be concluded that: 1) by internalizing the values contained in the Pesenggiri Piil in Poetry Study teaching materials, students are able to get positive values on poetry; 2) by involving local wisdom in teaching materials, students are able to absorb the norms and values contained in the Pesenggiri Piil; 3) entering the Industrial Revolution 4.0 era, teaching materials supported by interactive learning media based on Prezi Presentation are very relevant and more interesting.
\end{abstract}

\section{Kata kunci: bahan ajar Kajian Puisi, Piil Pesenggiri, Prezi Presentation}

\section{A. Pendahuluan}

Dasar hukum penerapan pembelajaran berbasis kearifan lokal pada pendidikan tinggi di Indonesia tertuang dalam Permenristekdikti Nomor 44 Tahun 2015 tentang Standar Nasional Pendidikan Tinggi (SNPT). Pembelajaran berbasis kearifan lokal merupakan salah satu perwujudan dari tujuan SNPT pasal 3 huruf a yang bertuliskan: "menjamin tercapainya tujuan pendidikan tinggi yang berperan strategis dalam mencerdaskan kehidupan bangsa, memajukan ilmu pengetahuan dan teknologi dengan menerapkan nilai humaniora serta pembudayaan dan pemberdayaan bangsa Indonesia yang berkelanjutan".

Selain tertuang pada tujuan SNPT, internalisasi kearifan lokal dalam pembelajaran juga tertuang dalam Standar Proses Pembelajaran SNPT pasal 11 yaitu, "Karakteristik proses pembelajaran sebagaimana dimaksud dalam Pasal 10 ayat (2) huruf a terdiri atas sifat interaktif, 
holistik, integratif, saintifik, kontekstual, tematik, efektif, kolaboratif, dan berpusat pada mahasiswa". Holistik sebagaimana dimaksud pada pasal 11 tersebut kemudian dijelaskan lebih lanjut sebagai proses pembelajaran yang mendorong terbentuknya pola pikir yang komprehensif dan luas dengan menginternalisasi keunggulan dan

kearifan lokal maupun nasional.

Internalisasi kearifan lokal dalam pembelajaran merupakan salah satu upaya dalam mewujudkan atau membentuk pembelajaran yang holistik. Kuntoro (2012:6) menjelaskan bahwa kearifan lokal digunakan guna mengindikasikan adanya suatu konsep bahwa dalam kehidupan sosial-budaya lokal terdapat suatu keluhuran, ketinggian nilai-nilai, kebenaran, kebaikan dan keindahan yang dihargai oleh warga masyarakat sehingga digunakan sebagai panduan atau pedoman untuk membangun pola hubungan di antara warga atau sebagai dasar untuk membangun tujuan hidup mereka yang ingin direalisasikan.

Kata kearifan lokal sendiri sering merujuk pada definisi budaya karena kearifan lokal juga diartikan sebagai serangkaian konsep sistem yang kompleks pada kehidupan masyarakat. Menurut Gondwe dan Nancy (2014) budaya merupakan sistem konsep kompleks, yang meliputi; nilai-nilai, norma-norma, kepercayaan dan praktek-praktek yang dibagi, dibuat dan diwariskan dari generasi ke generasi. Dengan demikian, kearifan lokal dapat diartikan sebagai konten-konten berupa nilai, norma, kepercayaan, keyakinan, yang dibuat dak diwariskan dari generasi ke generasi.

Dengan menginternalisasi kearifan lokal dalam proses pembelajaran, proses pembelajaran diharapkan tidak hanya menyentuh sisi intelegensi mahasiswa tetapi juga sisi pembentukan karakter. Untuk membentuk karakter mahasiswa, pengajar harus mampu memaksimalkan potensi lokal yang sudah sangat dekat dengan kehidupan mahasiswa. Berdasar hal tersebut, Piil Pesenggiri dipandang sebagai pilihan tepat guna mendukung pengajar dalam membentuk proses dan mencapai tujuan pembelajaran. Pada kenyataannya, internalisasi kearifan lokal Piil Pesenggiri pada proses pembelajaran belum diterapkan pada proses pembelajaran.

Piil Pesenggiri merupakan salah satu falsafah atau prinsip hidup yang dijadikan pedoman dalam berkepribadian, berprilaku, berinteraksi, bermasyarakat, dan berbangsa oleh masyarakat Lampung. Ali Imron (2005:18) mengungkapkan 
bahwa kehidupan sehari-hari masyarakat Lampung selalu berpedoman pada Pill Pesenggiri. Piil artinya rasa atau pendirian yang harus dipertahankan sedangkan pesenggiri pada dasarnya mengutamakan harga diri. Jadi dapat diartikan pill pesenggiri adalah harga diri. Pairulsyah (2013:168-169) mengungkapkan bahwa Falsafah Piil Pesinggiri adalah butir-butir falsafah yang bersumber dari kitab-kitab adat yang dianut oleh masyarakat Lampung. Piil Pesenggiri sendiri terdiri atas (1) nетиi nyimah, (2) nengah nyappur, (3) sakai, (4) sambaian, dan (5) juluk adek. Ratnaningsih (2019:2). Sedikit berbeda dengan Irianto dan Margareta, Puspawijaya menuturkan bahwa Piil Pesenggiri yang terdiri dari juluk adek, nemui nyimah, nengah nyappur, sakaisambaiyan, dan titie gemanttei," kata Rizani Puspawidjaja (Lampung Post, 20 Oktober 2006).

Sebagai falsafah dan prinsip yang mengikat hampir seluruh dimensi kehidupan masyarakat Lampung, Piil Pesenggiri yang terdiri dari 5 unsur. Kelima unsur tersebut adalah: (1) Juluk Adek (Gelar Adat); (2) Nemui Nyimah (Sikap Santun); (3) Nengah-Nyappur (Berada di Tengah atau Berbaur); (4) Sakai-Sambaiyan (Bergotong Royong); dan (5) Titie Gemantie (Aturan Hidup).
Kelima unsur tersebut kemudian akan diinternalisasi ke dalam proses pembelajaran pada bentuk bahan ajar.

Bahan ajar Kajian Puisi merupakan bahan ajar yang menjadi objek dalam penelitian ini. Setriwulan (2012:9) mengemukakan bahwa puisi adalah salah satu karya sastra yang disusun untuk mengekpresikan ide, gagasan, perasaan, serta emosi dari penyair dengan menggunakan kata-kata yang indah, melebihi bahasa yang digunakan seharihari. Tema yang diangkat dalam puisi dapat beragam bergantung pada apa yang dialami, dirasakan, dan dipikirkan oleh penyairnya. Tema dalam puisi dapat berupa: doa atau harapan, kritik atau saran, sindiran atau amarah, dan lain-lain. Motivasi penyair dalam memilih tema pada puisi biasanya bergantung dengan unsur yang dekat dengan penyairnya. Dengan demikian, puisi sangatlah dekat dengan tema-tema yang berkembang di masyarakat karena penyair adalah bagian dari masyarakat, seperti halnya berkaitan dengan Piil Pesenggiri.

Meskipun tidak secara langsung, nilai-nilai yang terkandung di dalam kelima unsur Piil Pesenggiri sering menjadi tema yang diangkat dalam suatu puisi. Dengan menginternalisasi nilai-nilai yang terkandung dalam Piil Pesenggiri dalam bahan ajar Kajian Puisi, mahasiswa 
diharapkan mampu mendapatkan nilainilai positif pada puisi tersebut. Selain itu, dengan melibatkan kearifan lokal dalam bahan ajar, mahasiswa diharapkan mampu menyerap norma dan nilai yang terkandung dalam Piil Pesenggiri. Memasuki era Revolusi Industri 4.0 ini, bahan ajar akan dikemas menjadi lebih menarik karena didukung dengan media pembelajaran interaktif berbasis Prezi Presentation.

$$
\text { Sadiman dkk }
$$
mendefinisikan media pembelajaran sebagai paduan antara bahan dan alat atau perpaduan antara software dan hadware yang digunakan untuk menyampaikan bahan ajar. Media pembelajaran memiliki peranan yang sangat penting dalam proses pembelajaran. Hamalik dalam Azhar (2010:15) menyampaikan bahwa penggunaan suatu media pembelajaran di dalam kegiatan pembelajaran mampu meningkatkan motivasi dan minat peserta didik untuk mengikuti proses pembelajaran. Oleh karena itu, seorang pengajar harus mampu memilih dan menggunakan media pembelajaran secara baik. Dengan media pembelajaran yang menarik, minat dan motivasi mahasiswa akan lebih meningkat.

Prezi Presentation adalah aplikasi berbasis presentasi yang lebih interaktif dan fitur yang lebih menarik dari Ms. Powerpoint milik Microsoft dan Libre Impress milik Libre. Fischer (2009:3) mengatakan salah satu pembuat aplikasi Prezi Presentation, Prezi Presentation didefinisikan sebagai aplikasi presentasi berbasis website (daring) yang memiliki kelebihan pada sisi visual, interaktif, dan mampu membangun sinkronisasi antara pengajar dan audience. Keunggulan dari Prezi Presentation diambil dari situs resminya adalah sebagai berikut:

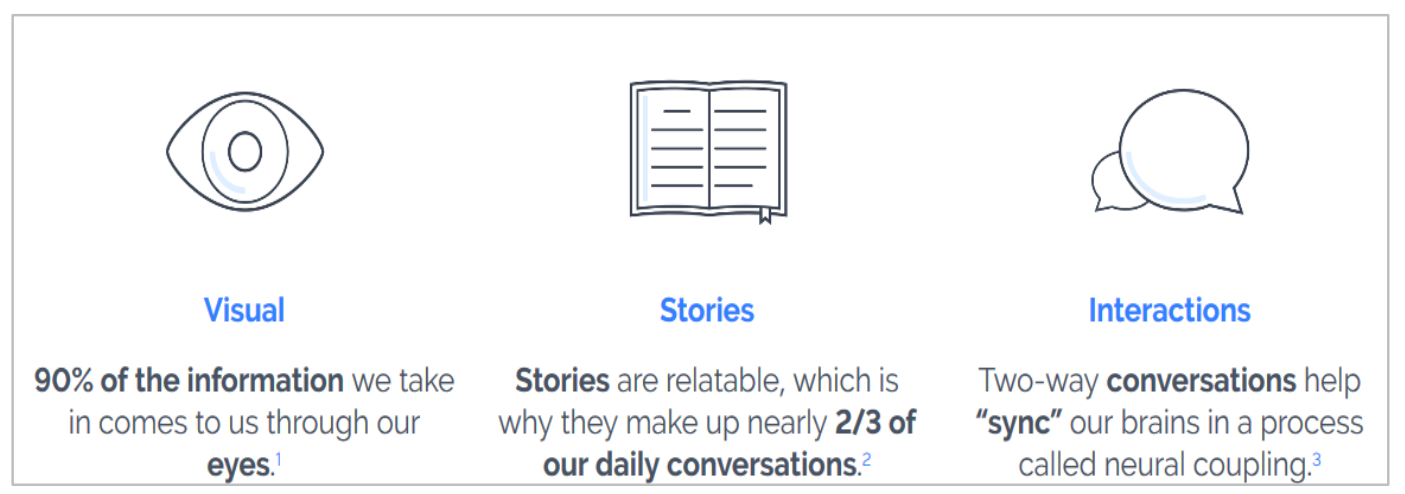

B. Bahan Ajar Kajian Puisi Berbasis Kearifan Lokal (Piil Pesenggiri)
Proses pembuatan bahan ajar berbasis kearifan lokal (Piil Pesenggiri) dilakukan secara berulang-ulang. Proses pembuatan bahan ajar diawali dengan 
melakukan proses revisi beberapa kali. Proses revisi masing-masing ahli berbeda satu dengan yang lain. Ahli materi memberikan saran dan komentar sebanyak empat kali, sehingga proses revisi yang dilakukan sebanyak tiga kali. Ahli media memberikan saran sebanyak tiga kali, sehingga revisi yang dilakukan sebanyak dua kali. Ahli bahasa memberikan saran dan komentar sebanyak dua kali, sehingga revisi dilakukan sebanyak satu kali. Berikut ini adalah deskripsi panilaian bahan ajar dari beberapa validator.

\section{Penilaian Bahan Ajar dari Beberapa Validator}

Proses validasi bahan ajar dilakukan oleh beberapa ahli. Ahli yang dilibatkan terdiri atas tiga bagian: ahli materi, ahli media, dan ahli bahasa. Berikut ini adalah data validator ahli materi berserta indikator penilaiannya.

1. Validator Ahli Materi

\begin{tabular}{|c|c|}
\hline & Validator Ahli Materi \\
\hline Nama & Drs. Juhardi Basri, M.Pd. \\
\hline Pekerjaan & $\begin{array}{l}\text { - Dosen di Prodi Bahasa } \\
\text { dan Sastra Indonesia } \\
\text { - Sastrawan Lampung }\end{array}$ \\
\hline $\begin{array}{l}\text { Indikator } \\
\text { penilaian }\end{array}$ & $\begin{array}{l}\text { - Kesesuaian materi } \\
\text { dengan perangkat } \\
\text { pembelajaran }\end{array}$ \\
\hline
\end{tabular}

\begin{tabular}{|l|l|}
\hline$\bullet$ Keakuratan materi \\
$\bullet$ Kemutakhiran materi \\
$\bullet$ Mendorong \\
keingintahuan \\
$\bullet$ Teknik penyajian \\
$\bullet$ Kelangkapan penyajian \\
$\bullet$ Keruntunan konsep/alur \\
berpikir \\
$\bullet$ Sistem evaluasi
\end{tabular}

2. Validator Ahli Media

\begin{tabular}{|c|l|}
\hline & Validator Ahli Media \\
\hline Nama & Khusnul Khotimah, M.T.I. \\
\hline Pekerjaan & $\begin{array}{l}\text { Dosen di Prodi Sistem dan } \\
\text { Teknologi Informasi }\end{array}$ \\
\hline \multirow{2}{*}{$\begin{array}{l}\text { Indikator } \\
\text { penilaian }\end{array}$} & $\begin{array}{l}\text { - } \text { Kermat bahan ajar } \\
\text { Megrafikan bahan ajar }\end{array}$ \\
& Media presentation \\
\hline
\end{tabular}

3. Validator Ahli Bahasa

\begin{tabular}{|c|l|}
\hline & Validator Ahli Bahasa \\
\hline Nama & Dr. Sri Widayati, M.Hum. \\
\hline Pekerjaan & $\begin{array}{l}\text { Dosen di Prodi Bahasa dan } \\
\text { Sastra Indonesia }\end{array}$ \\
\hline $\begin{array}{r}\text { Indikator } \\
\text { penilaian }\end{array}$ & $\bullet \quad$ Lugas \\
\hline
\end{tabular}




\begin{tabular}{|l|ll|}
\hline & $\bullet$ & Dialogis dan interaktif \\
& peserta didik & \\
$\bullet$ & Kesesuaian & dengan \\
& kaidah & Bahasa \\
& Indonesia & \\
\hline
\end{tabular}

Berdasarkan beberapa ahli dan indikator penilaian di atas, dilakukan proses validasi bahan ajar agar tercipta bahan ajar yang ebnar-benar relevan. Revisi bahan ajar didapat dari saran dan komentar masing-masing validator ahli. Proses validasi deegan ahli materi menghasilkan tiga kali revisi. Proses validasi dengan ahli media menghasilkan tiga kali revisi dua kali revisi. Proses validasi dengan ahli bahasa menghasilkan satu kali revisi. Berikut ini adalah pemaparan dari masing-masing validator ahli.

\section{Validator Ahli Materi}

Saran dan komentar validator ahli materi menjadi tolok ukur kedalaman materi dalam bahan ajar. Berikut ini merupakan gambaran singkat saran dan komentar yang diberikan.

\section{Tabel}

\section{Saran dan Komentar Validator Ahli Materi}

\begin{tabular}{|c|c|c|c|}
\hline No & Indikator Penilaian & Saran & Tindakan \\
\hline \multicolumn{4}{|c|}{ Penilaian Pertama } \\
\hline 1 & Mendorong keingintahuan & $\begin{array}{l}\text { Tambahkan gambar- } \\
\text { gambar menarik terkait } \\
\text { budaya Lampung. }\end{array}$ & $\begin{array}{l}\text { Menambahkan gambar- } \\
\text { gambar terkait budaya } \\
\text { Lampung }\end{array}$ \\
\hline 2 & Kelengkapan Penyajian & $\begin{array}{l}\text { Tambahkan pentingnya } \\
\text { melestarikan } \\
\text { daerah budyaa } \\
\text { Lampung) pada bagian } \\
\text { pendahuluan. }\end{array}$ & $\begin{array}{l}\text { Menambahkan uraian } \\
\text { tentang pentingnya } \\
\text { melestarikan baudaya } \\
\text { Lampung }\end{array}$ \\
\hline 3 & $\begin{array}{l}\text { Keruntutan Konsep/ alur } \\
\text { berpikir }\end{array}$ & $\begin{array}{l}\text { Gunakan contoh analisis } \\
\text { dari yang mudah (secara } \\
\text { eksplisit) ke yang sulit } \\
\text { (implisit). }\end{array}$ & $\begin{array}{lrr}\text { Merunut } & \text { contoh } \\
\text { analisis } & \text { dari } & \text { yang } \\
\text { bersifat } & \text { eksplisit } & \text { ke } \\
\text { implisit. } & & \\
\end{array}$ \\
\hline \multicolumn{4}{|c|}{ Revisi pertama } \\
\hline 1 & Teknik Penyajian & $\begin{array}{l}\text { Gunakan alat bantu } \\
\text { (berupa gambar dsb.) } \\
\text { untuk membuat teknik } \\
\text { penyajian lebih menarik }\end{array}$ & $\begin{array}{l}\text { Menggunkaan } \begin{array}{l}\text { alat } \\
\text { dalam } \\
\text { bantu } \\
\text { menyampiakan materi. }\end{array}\end{array}$ \\
\hline 2 & Sistem Evaluasi & $\begin{array}{l}\text { Buat pedoman yang jelas } \\
\text { terkait system evaluasi. }\end{array}$ & $\begin{array}{l}\text { Membuat pedoman } \\
\text { sistem evaluasi yang } \\
\text { jelas. }\end{array}$ \\
\hline \multicolumn{4}{|c|}{ Revisi kedua } \\
\hline 1 & Sistem Evaluasi & Indikator pada pedoman & Memperbaiki indikator \\
\hline
\end{tabular}




\begin{tabular}{|c|l|l|l|}
\hline No & \multicolumn{1}{|c|}{ Indikator Penilaian } & \multicolumn{1}{|c|}{ Saran } & \multicolumn{1}{c|}{ Tindakan } \\
\hline \multicolumn{1}{|c|}{} & $\begin{array}{l}\text { sistem evaluasi belum } \\
\text { detail }\end{array}$ & penilaian \\
\hline \multicolumn{2}{|l|}{ Revisi ketiga } & $\begin{array}{l}\text { Indikator pada pedoman } \\
\text { sistem evaluasi belum } \\
\text { detail }\end{array}$ & $\begin{array}{l}\text { Memperbaiki indikator } \\
\text { penilaian }\end{array}$ \\
\hline 1 & Sistem Evaluasi &
\end{tabular}

Validator Ahli Media

Validator ahli media memberikan saran terkait pemberian informasi dengan media prezi presentation belum maksimal karena hanya menggunakan beberapa template. Ahli media mengungkapkan bergamnya template yang ada di dalam aplikasi Prezi Presentation dapat digunakan agar bahan ajar lebih interaktif dan animatif.

\section{Validator Ahli Bahasa}

Validator ahli bahasa hnaya memberikan satu kali saran dan komentar. Hal ini terjadi karena sedikit sekali kata ataupun kalimat yang menyimpang dari kadiah penggunaan ejaan dan istilah. Beberapa hal yang dikomentari ahli bahasa terkait kesalahan pengetikan yang berimbas pada ketidaksesuaian terhadap kaidah bahasa Indonesia.

\section{Simpulan}

Berdasarkan hasil penelitian dapat disimpulkan bahwa:

1) dengan menginternalisasi nilai-nilai yang terkandung dalam Piil Pesenggiri dalam bahan ajar Kajian Puisi, mahasiswa mampu mendapatkan nilai-nilai positif pada puisi;

2) dengan melibatkan kearifan lokal dalam bahan ajar, mahasiswa mampu menyerap norma dan nilai yang terkandung dalam Piil Pesenggiri;

3) memasuki era Revolusi Industri 4.0, bahan ajar yang didukung dengan media pembelajaran interaktif berbasis Prezi Presentation sangat relevan dan lebih menarik.

\section{Daftar Rujukan}

Ali Imron. 2005. Pola Perkawinan Saibatin. Universitas Lampung, Bandar Lampung.

Azhar, Arsyad. (2010). Media Pembelajaran. Jakarta: Raja Grafindo Persada. 
Fischer, Adam Somlai (2009). Prezi Presentation Presentation Software. Hungaria: Prezi Presentation Inc.

Irianto,Sulistyowati dan Risma Margaretha. 2011. Piil Pesenggiri: Modal Budaya dan Strategi Identitas Ulun Lampung. (Makara, Sosial Humaniora).

Lampung Post. 2006, 20 Oktober. Piil Pesenggiri.

Pairulsyah. 2013. Kualitas Pelayanan Publik Samsat Lampung dalam Perspektif Budaya Piil Pesenggiri. Fiat Justisia Jurnal Ilmu Hukum, 7 (2), 168-180.

Pargito. 2010. Penelitian dan Pengembangan Bidang Pendidikan. Universitas Lampung.

Ratnaningsih, D. (2019). Nilai Budaya Lampung (Piil Pesenggiri) dalam Sastra Lisan Pepaccur Masyarakat Lampung Pepadun dalam Prosesi Pengambilan Gelar Adat. JURNAL PESONA, 5(1), 1-9.

Sadiman, dkk. (1996). Media Pendidikan Pengertian, Pengembangan, dan Pemanfaatannya. Jakarta: Raja Grafindo Persada.

Setriwulan, Indrawati (2012) Kajian Struktural dan Semiotik Dalam Puisi Karya Victor Hugo. 